

\section{Agenda \\ Goals}

Hand outs

Make yourself comfortable

Make it worth your while Introductions 


\section{Facilitators}

Susan Beatty

Univ. of Calgary Library, Canada

Hester Mountifield

Univ. of Auckland Library 
What is an Information Commons?

Models and History 
- "a space specifically designed to organized workspace and service delivery around the integrated digital environment"

Beagle, 1999 


\section{Visionaries and Techies}

- Paradigm shift to the integrated digital world

- Philip Tompkins

- Need to break the barriers between different cultures in the academy 


\section{Evolution of Service Models}

- Unique needs of community of users

- Reflect culture

- Not necessarily one model of service

- Continuous improvement leading to transformation 


\section{Models}

3 categories

1.Computer lab

2.Integrated facility

- Library only

- Library joint

3. Information Commons building 


\section{Computer lab}

- Technology based - hardware and software

- Not necessarily part of the library

- Self-service or range of assistance and instruction

- Basic to advanced technology

- Example: ScotiaBank Information Commons University of Toronto 


\section{Integrated Library only}

- Reference and technical assistance

- Variable size and service program

- Seldom other collaborators

- Possible technical assistance from others (in front or in back) or provide through own staff

- Instruction is information literacy instruction

- Example: University of Southern California Leavey Library 


\section{Library Joint Facility}

- Collaborators: library, IT and/or others

- Library based with one or more service desks

- Likely to see other collaborators to take user beyond digital environment to the learning environment

- Learning technologies, writing centers, career services, tutoring, plus more assistance acquiring high tech skills (e.g. media suites)

- Example: University of North Carolina, Charlotte, University of Calgary 


\section{Information \\ Commons building}

- Library-based or New facility with services for faculty/students

- Something completely different and new

- Multiple partners - limited only by imagination and leadership

- Educational services, student services, media centers, museums

- Potential for integration, seamless delivery

- Example: University of Arizona, University of Auckland, new $U$ of $C$ Campus Calgary Digital Library 


\section{Some other examples}

- University of Sheffield

- Indiana University

- University of Guelph 
- From Information Commons to Learning Commons Beagle 2004

- IC Adjustment: computer lab

- IC Isolated change: library-centric - with assistance

- LC far-reaching change integration of functions formally carried out within the library to others formally carried out beyond the library - essentially collaborative 


\section{Learning Commons as transformational change}

- Layering of campus wide learning initiatives

- E.g. core curriculum innovation

- Learning objects such as D-Space

- Service delivery to students enhanced with multiple service delivery profiles projected at the needs of faculty.

Is this e-literacy at its highest level - where faculty and students have an enriched suite of services and toolsets and work together in a collaborative setting? 


\section{Activity}

Planning collaboration

"I.Q." test

evit2006 


\section{Elements of an Information Commons}




\section{Net Gen}

Multi-media

Connected

Multitasking

Experimental

Collaborative

Integrated

Expectations
Graphics/visual/sound

Mobile phones, iPod, MP3, PDAs, $\mathrm{IM}$, wireless

$\mathrm{IM}$, gaming, searching, non linear Visual interfaces, streaming media

Chat, screen sharing, P2P, groups

Content, service, coaching

Producers \& consumers 


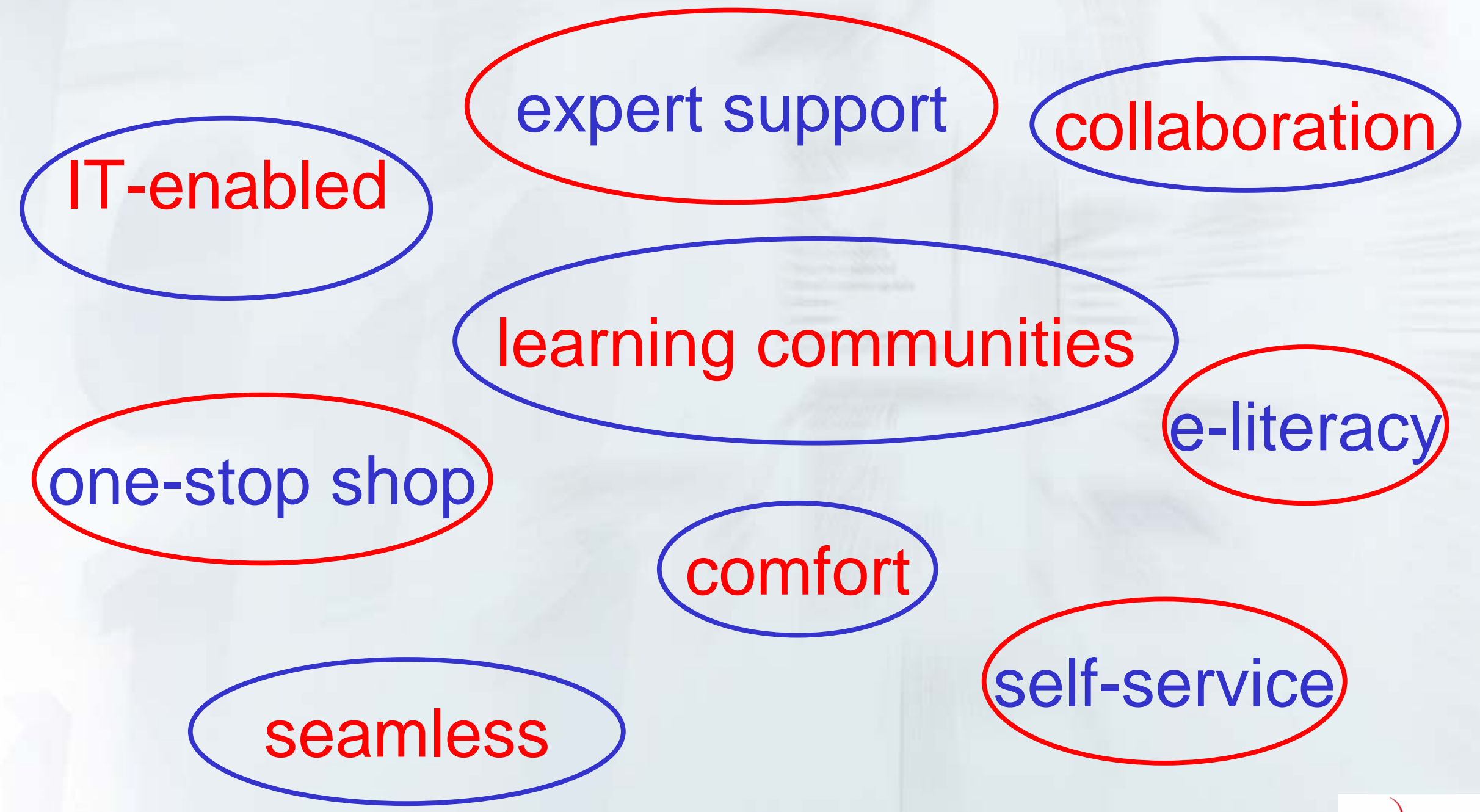

evit2006 


\section{Physical}

Location, location, location

Variety of spaces

Flexible furniture arrangement

Access

Security 


\section{Computing}

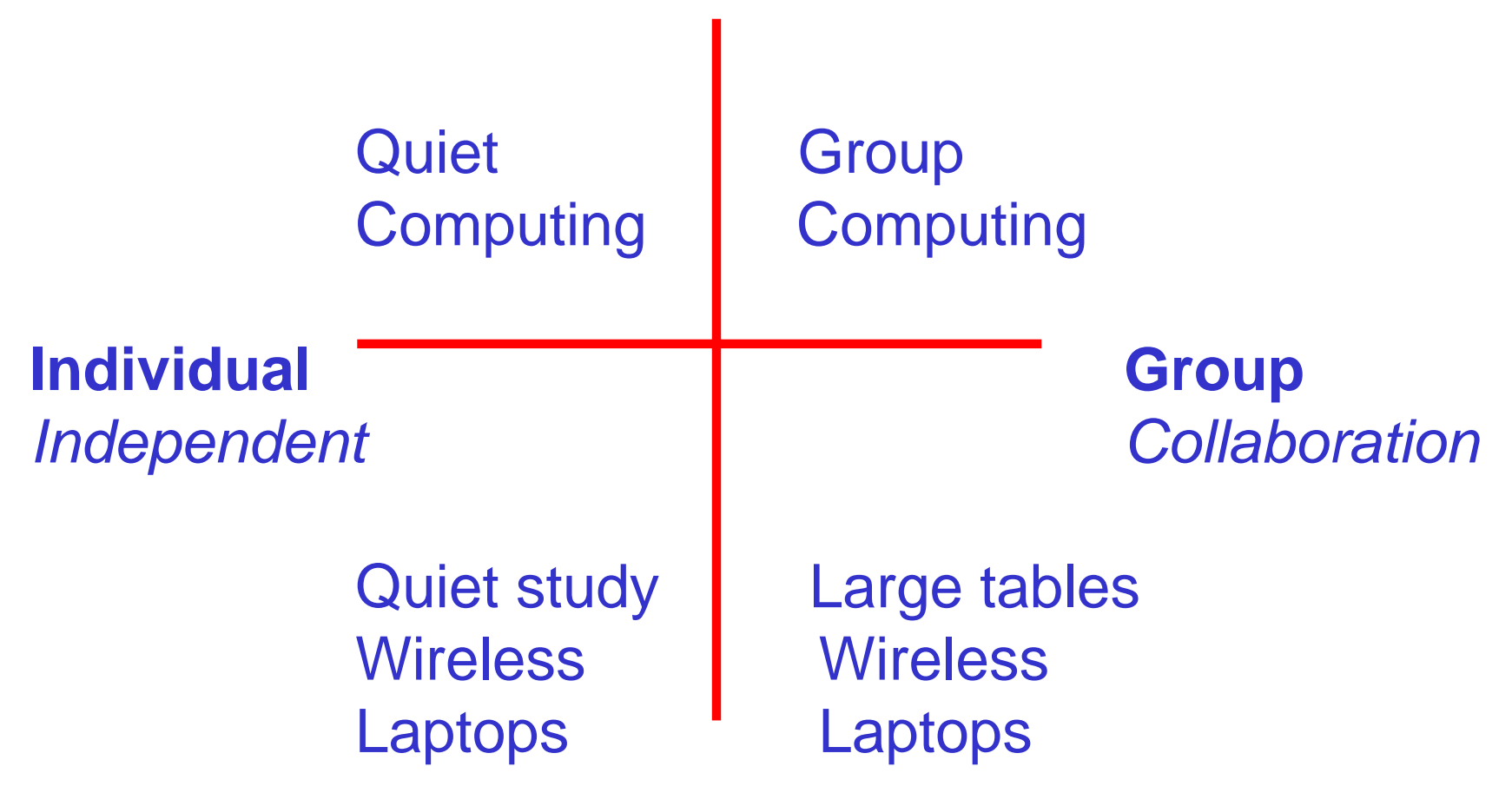

Techno-lite 


\section{Virtual}

IT infrastructure

Hardware: support \& maintenance

Software: productivity \& presentation

E-content

Enterprise systems

Authentication \& authorisation

Systems security

Desktop: management \& future development 


\section{Learning}

Learning communities: group work, collaboration, peer coaching

Independent or solitary

IT enabled and IT free

Learning Commons: collaboration

with campus-wide learning

developments; integration of e-

content \& e-services with LMS

leading to core curriculum revision 


\section{Service}

Service expectation \& demand for quality

New service models

Integrated dynamic learning support

Continuum of service

Multi-skilled staff

Self-service options

Single or multiple service points 


\section{Social}

Recreational spaces

Community building

Social learning

Models modern work environments

Retail \& food 


\section{Management}

Collaboration, merger or co-location

Communication

Performance measures

Staffing issues

Training

Budget

Facilities management 


\section{Collaboration}

Who?

Librarians, IT Professionals,

Learning Advisors, Instructional

Technologists, Multi-media

Producers, Writing Advisors,

Language Consultants

Sometimes also

Student Administrators, Counsellors, Health Professionals, International student support

eVit2006 


\section{Collaboration}

Why?

Complex \& multidimensional learning environment

External \& internal pressures

Combine expertise, resources,

facilities

Symbiotic relationships

synergistic outcomes

eVit2006 


\section{Collaboration}

Vision \& relationships

Structure, responsibilities \&

communication

Authority \& accountability

Resources \& rewards 


\section{Collaboration}

\section{People}

Success is based on a cross-section of stakeholders, and not dependent on a single personality

Requires mutual respect, trust, mentoring and a sense of humour Most critical factor - brings the space to life 


\section{Collaboration}

\section{Challenges}

Collaboration is complex

Organisational \& administrative lines

Differences

budget structures

reward systems

performance measures

cultures

Continuous organisational development 


\section{Outcome?}

Just another computer lab

Reference area with rows of computers

Fiefdom of ervice points

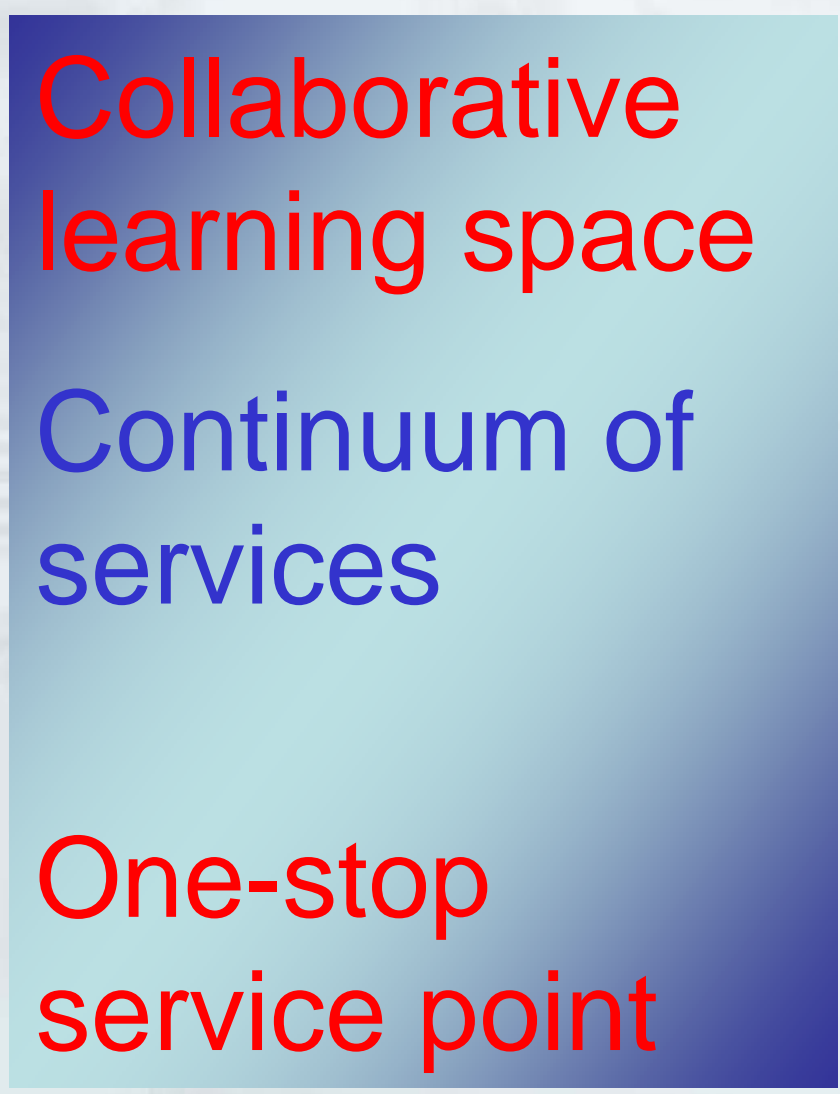




\section{Busiest place on campus?}

2003

Door count

Queries

Network logins

Pages printed

Short Loan

Photocopies

\begin{tabular}{r|r}
2003 & 2005 \\
$2,141,385$ & $2,283,332$ \\
38,721 & 36,464 \\
837,427 & $1,263,627$ \\
$2,058,869$ & $3,763,137$ \\
154,621 & 200,938 \\
$1,258,488$ & $1,081,938$
\end{tabular}




\section{$x^{-1}$ \\ a $-a$ \\ $21-1$ ,}

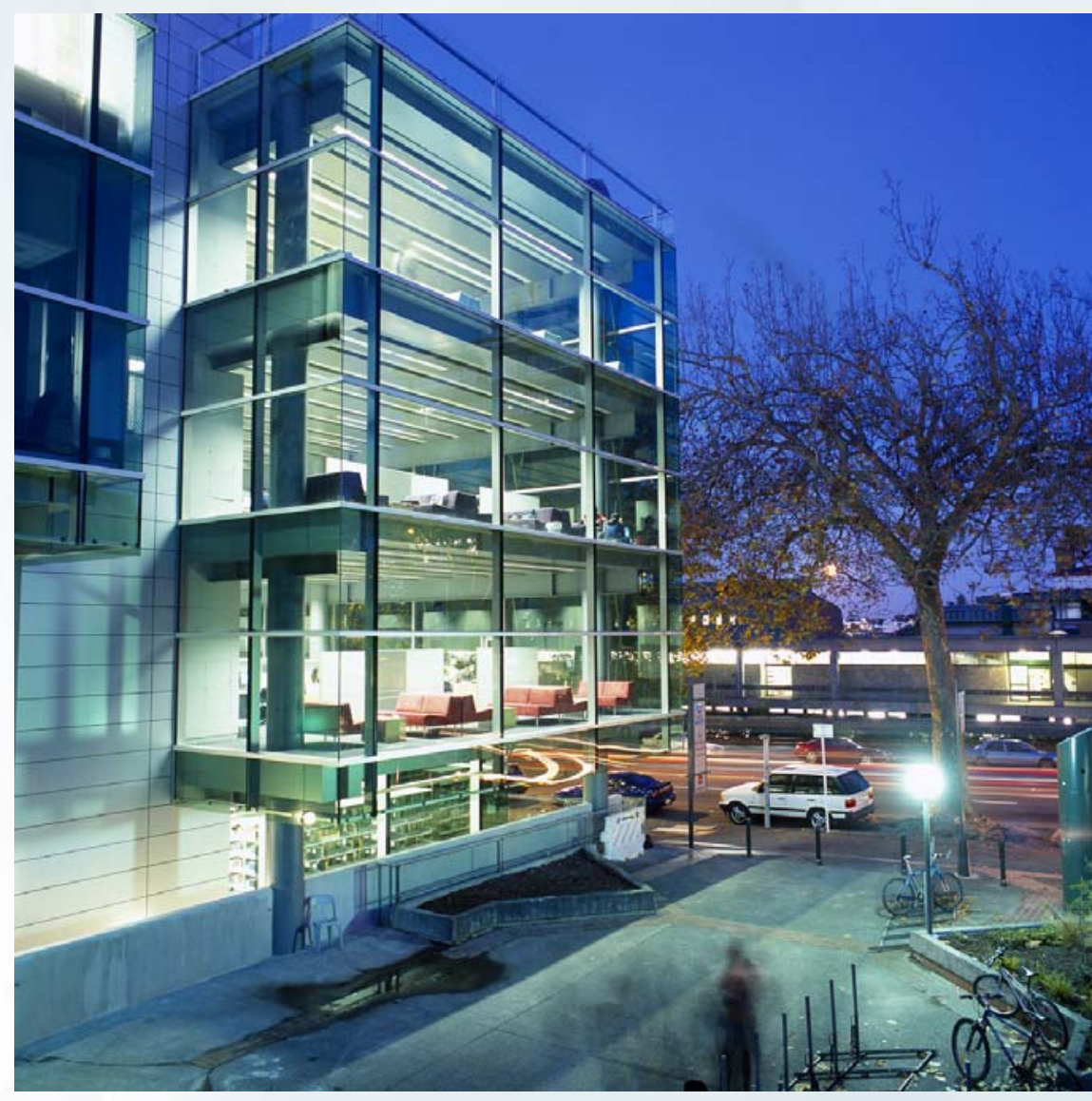

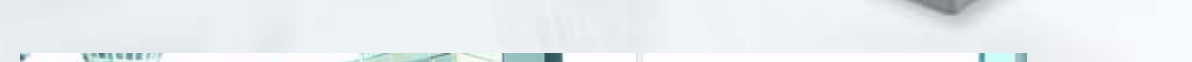

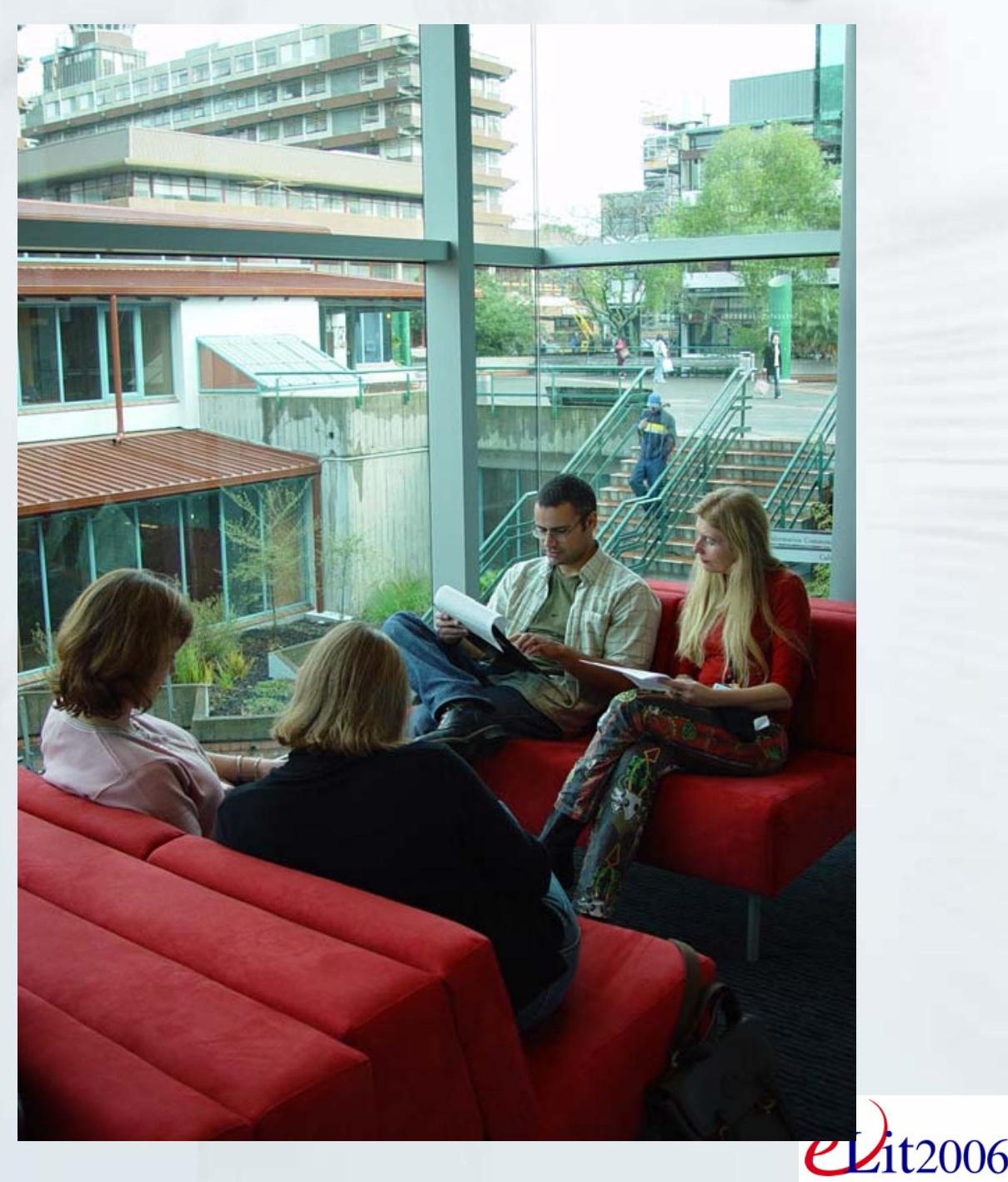




\title{
Advantages of Integration
}

\author{
User \\ Library \\ Collaborators \\ Academy
}

evit2006 


\section{Users}

- One stop service

- Help when and where they need it Expertise at all levels

- Good technology infrastructure - saves $\$ \$ \$$

- Collaborative learning environment 


\section{Library}

- Transforms library - service and staff

- Library becomes a campus centre learning and social centre

- Library's role in learning support is made more clear

- Improved use of resources

- Library becomes more politically significant within the academy 


\section{Collaborators}

- Tie yourself to a star

- Sum of us is better than the one of us

- Re-enforces viability of face to face service all the while ...

- Integrating virtual services 


\section{Academy}

- Strategic success is good

- Seen to be leader in change which will lead to more change

- Seen to be leader in use of digital environment

- Effective and efficient use of resources

- High profile attracts more funding 


\section{Eliteracy@UoA}

\section{Strategic plan \\ Academic plan \\ Graduate profiles}

Institutional Information Literacy policy

evit2006 


\section{Collaboration}

Academic Departments

University Library

Centre for Academic Development (CAD)

Graduate Centre

Career Centre

Student Administration 


\section{Collaboration}

Academic Dept.

University Library

\section{Information literacy}

\begin{tabular}{lrrrr} 
& 2005 & 2004 & 2003 & 2002 \\
\cline { 2 - 5 } Courses & 2056 & 1838 & 1527 & 898 \\
Participants & 27797 & 21606 & 17924 & 13409
\end{tabular}

evit2006 


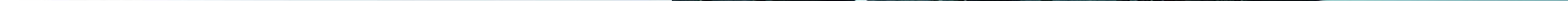




\section{BBIM BUSINESS 191 Course Page (VLE)}

Academic Honesty Assistance Tutorial (Alia)

This integrated self-paced instructional tutorial introduces new students to western academic notions of knowedge; the purpose and practice of acknoweddging ideas, namely referencing, and effective strategjes for awoid plagiarism in their own work

Academic Honesty Tutorial

\section{Information Skills Modules}

The information modules are a self paced 4 week online cousse. They are woth $5 \%$ of your course grade and reinforce skills essential for academic success. The frist week of semester you will have a session with the BElM Libratian on your campus who will explain how to do the modules. For 4 weeks there will be a weekly online tutorial on the BBlM homepage, followed by a matching Library Test of multi choice questions in Cecil, the University of Auckland's learring platiform.

The module topics are:

1. Research \& critical thinking skills

2.Jsing electronic information sources

3.Jusing the Intemet effectively to locate business information

4.Locating New Zealand industry information 


\section{Librarian -Teacher Collaboration: Facilitating IL through shared design, delivery and assessment of meaningful e-learning experiences}

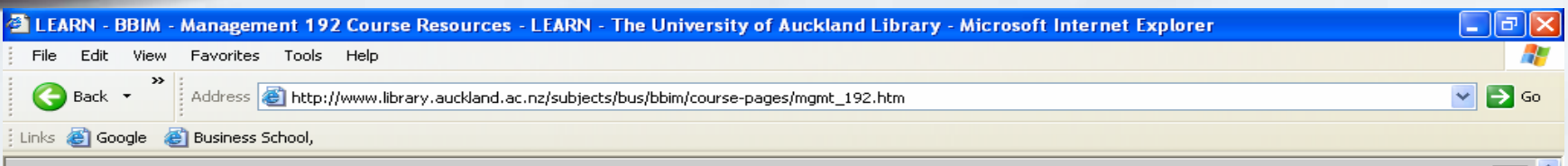

New Zealand industry and product information

目 InfoLit 04 Int

welcome to th Before starting This test is ope You have unlin If you have an Lyone Mitchell Charles Knight

InfoLit $05 \mathrm{R}$

welcome to Lit Before startin This test is op If you have an Charles Knight
This module is This (이
8 STEPS

- Search Voyager to find any books on the industry

- Find recent industry news and articles

- Look at industry reports, profiles and overviews [databases; internet sites]

- Look for company information

- Look for industry association and organisation websites

- Use an internet search engine to find additional industry overviews and global scenarios

- Identify the ANZSIC code and industry description

- Find statistics including trade and market share statistics

PLUS.

- Patents, standards, trademarks

- Industry analysis: what is an industry analysis

- Doing business in New Zealand

1. Search Voyager to find any books on the industry $\square$

With Voyager it is best to begin with a Guided keyword search rather than a Subject Heading search, unless you know the exact structure of the subject heading. For example, books and journals on the telecommunications industry may have any of the following subject headings:

telecommunication new zealand

telecommunication policy new zealand

telecommunication deregulation new zealand

telecommunication systems new zealand 


\section{Law Programme}

Legal Research 1 LAW299

- Compulsory

- Full semester

- 5 taught classes

- Small groups

- 347 students

- Marked worksheets

- Online modules and Tests

- $50 \%$ course work, $50 \%$ final test

- Pass mark 80\%

- Pass/Fail

- Certificate
Legal Research 2 LAW399

- Core in degree

- Full semester

- 10 point course

- 2 hours per week

- 3 streams of $100+$

- Marked worksheets

- Online modules \& Tests

- $50 \%$ course work, $50 \%$ research trail

- Graded
Legal Research \& Methodology LAW788

- Compulsory

- Modular

- 2 days intensive

- Choice of online or handson learning for 5 database training classes

- Selection of 9 methodology classes

- Assessment = research trail for substantive law paper

- Pass/Fail 


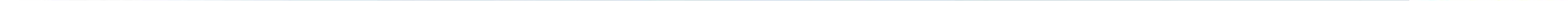




\section{Collaboration}

\section{University Library}

CAD

\section{Information literacy}

\section{IT literacy}

Professional development 
New to the Library?

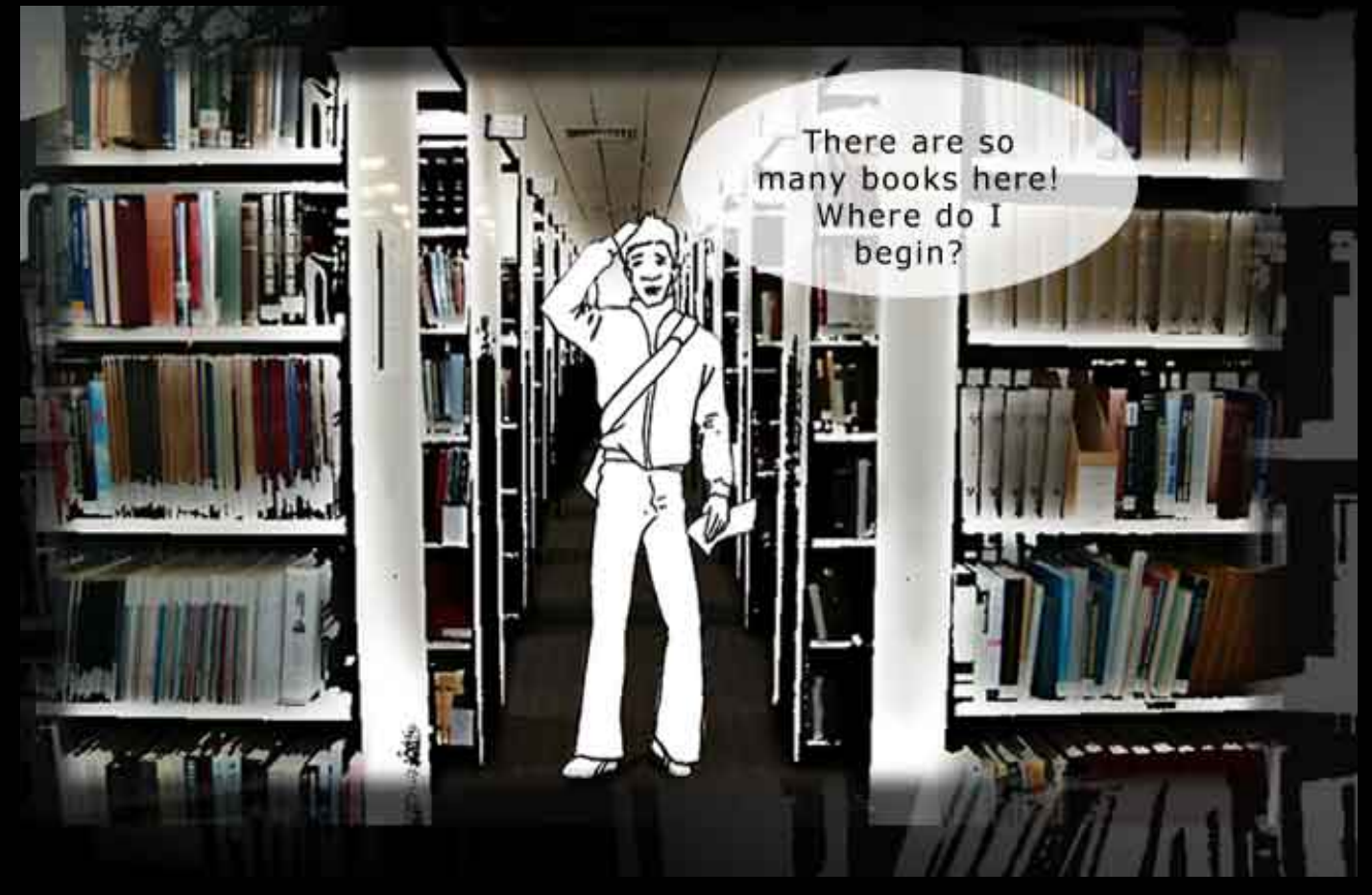

\section{Feeling LOST?}

LEARN - umw. I i brary. auckl and. ac. nz $\gg$ New Voyager Tut or i al D Start Tutorial 




\section{Follow the story...}
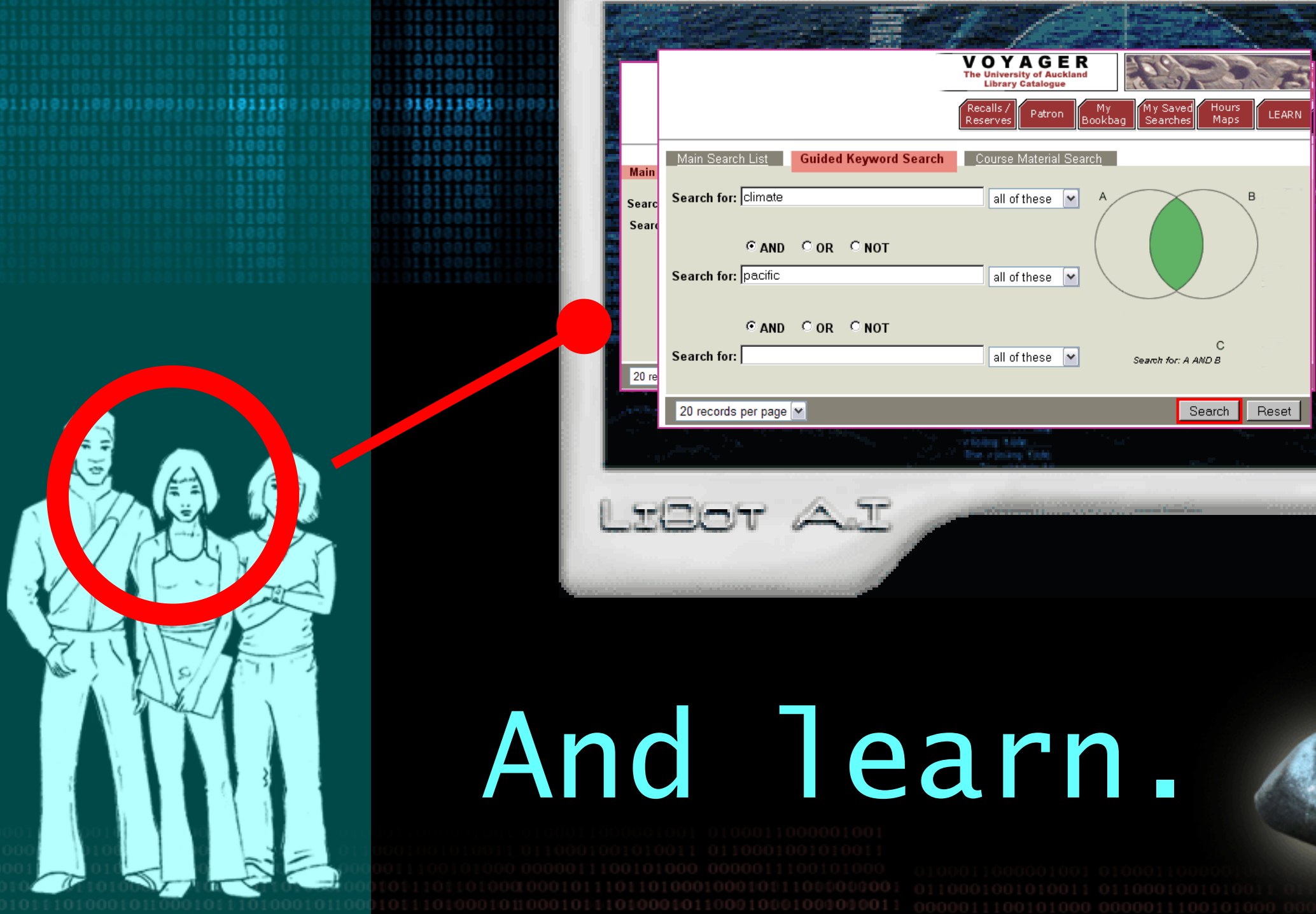

LIEOT AIT

And Tearn. 


\section{Collaboration}

\section{Graduate Centre}

University Library

CAD

Career Centre

\section{Graduate Capabilities} Programme 


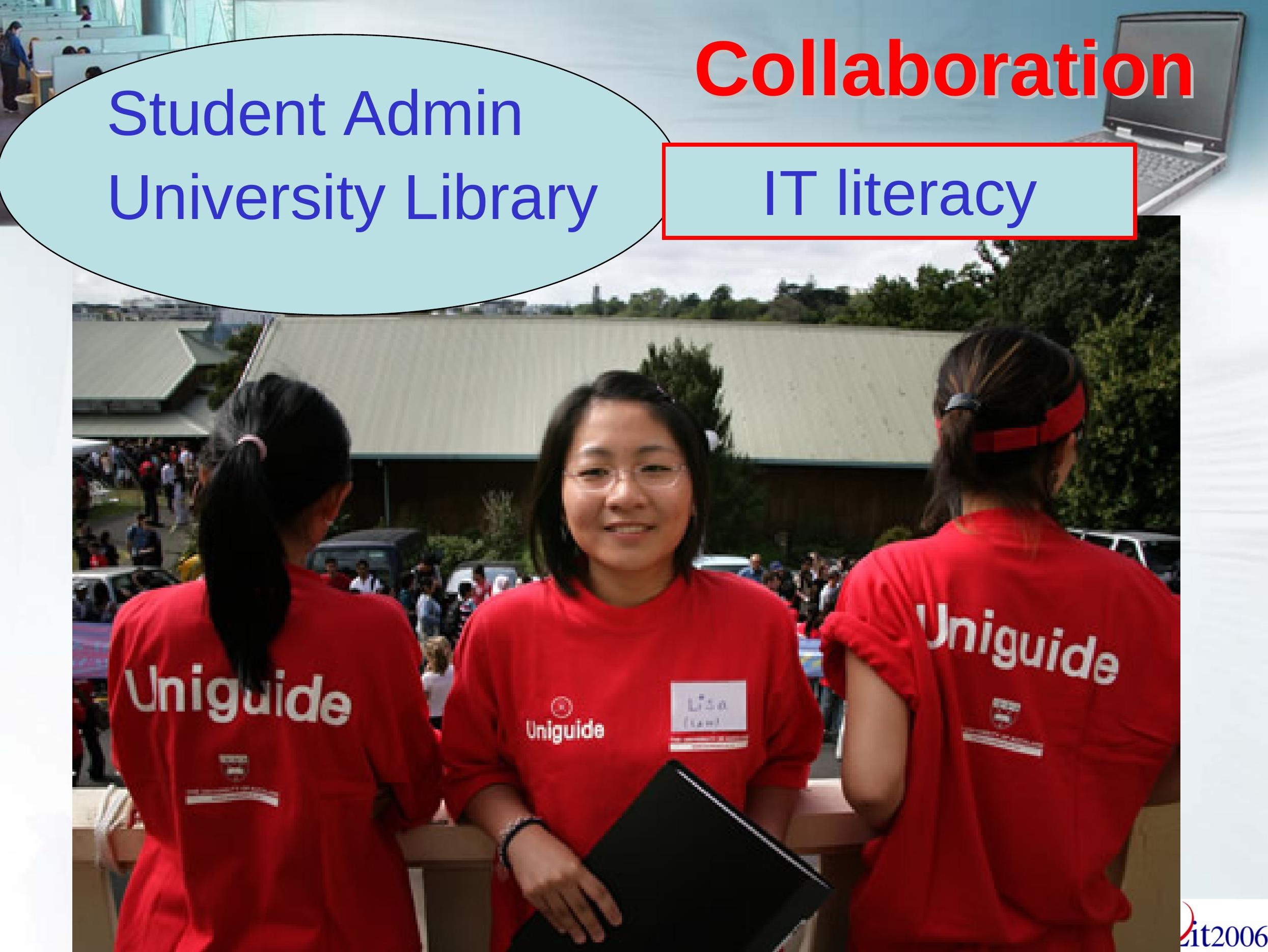




\section{E-literacy at \\ University of Calgary}

- E-Lit = information literacy and technical

literacy

- Students and faculty - separate and integrated

- Information literacy - Library

- Technical literacy - IT, Teaching and Learning Centre 


\section{E-Lit Collaborators}

- Information Commons

- Experts from both literacies

- Classroom facilities and learning infrastructure

- Formal and informal instruction

- Face to face and virtual 


\section{Faculty}

- Teaching and Learning Centre

- Experts in technology and teaching and learning

- Liaison librarians

- Experts in information resources

- Information Technology

- Experts in technology 


\section{Instruction in the IC}

- General

- Library

- Productivity Software

- http://library.ucalgary.ca/services/library\&computerinstr uction/

- Specialized

- IL in the classroom within the course

- IL and IT in the classroom within the course

- IT and TLC in the classroom within the course

- IL and IT and TLC in the classroom within the course 


\section{Faculty Technology Days}

- Collaborative instruction for faculty and grad students

- Library, IT and Teaching and Learning

Centre

- Organized and hosted in the Library

- This year 36 sessions over three days

- www.ucalgary.ca/ftd 


\section{Further e-learning goals}

- Embedded within course management system - links to subject, librarian, technical assistance

- Virtual assistance - reference and technical

- Podcasting, video streaming, self-guided tutorials, or ???

- other Collaborators

- Campus Calgary Digital Library http://ccoll.ucalgary.ca/ 
Planning an Information Commons E-literacy action plan 


\section{Any questions?}

evit2006 